differences were found to be significant when bereavement occurred between the ages of 5 and 15 years than younger, though a high proportion of female drug addicts and of schizophrenics of both sexes had experienced bereavement between birth and 4 years old.

In another study ${ }^{10}$ analysis of the effects of age on bereavement was ingeniously controlled by using the patients' own healthy sibs. It was concluded that no significant difference existed between the patients and their siblings in respect of age at parent's death. Of 13 previous studies reviewed by the author, four found that death of the mother, but not of the father, was unusually common in the childhood of schizophrenics ; one study found death of the father but not of the mother was more frequent ; in three studies the death of one or other parent appeared significant; and in five studies no significant differences from the control groups were found.

Among recent studies in other psychiatric groups increased parental loss has been found among depressives, ${ }^{11}{ }^{12}$ suicides, ${ }^{13}$ attempted suicides, ${ }^{14} 15$ sociopaths, ${ }^{16}$ alcoholics, ${ }^{17}$ and elderly neurotics, ${ }^{18}$ while other studies have not shown any increase in loss of parents. ${ }^{19-21}$ The varying results emphasize the many methodological pitfalls in this field. ${ }^{22}$ At the same time the range of disorders influenced by parental loss is so broad as to suggest that the effects of bereavement are not specific but increase the general susceptibility to psychiatric disorder by adversely affecting the process of personality development. In their papers on aetiological factors in sttempted suicides Greer and colleagues ${ }^{23} 24$ have in fact suggested that bereavement and broken homes may militate against the development of socially adjusted personalities.

Bowlby's original observations were made on juvenile delinquents, and it is here that the evidence for adverse effects of "broken homes" and parental deprivation is probably strongest. Nevertheless, the relationship between early separation or deprivation and delinquency remains problematical.4 While retrospective studies of delinquents usually show that a high proportion of them suffered deprivation in early childhood, follow-up studies of children who have suffered early, prolonged, and severe deprivation show that only a very few become delinquent. Apparently neglect and

Goldfarb, W., f. exp. Educ., 1943, 12, 106.

Spitz, R. A., and Wolf, K. M., Psychoanal. Stud. Child, 1946, 2, 313. Bowlby, J., Maternal Care and Mental Health, Wld Hlth Org. Monogr. Ser., No. 2, 1951 .

Deprivation of Maternal Care, Wld Hlth Org. Publ. Hlth Pap., No. 14, 1962.

Wootton, B., ibid., p. 63.

- Yaotton, B., ibid., p. Psychol. Bull., 1961, 58, 459.

- Yarrow, L. J., Psychol. Bull., 1961, 58, 459. Hlth Pap., No. 14, 1962, p. 31 .

- Lewis, H., Deprived Chaldren, 1954. London.

- Dennehy, C. M., Brit. F. Psychiat., 1966, 112, 1049

10 Granville-Grossman, K. L., ibid., 1966, 112, 1027.

1 Brown, F., f. ment. Sci., 1961, $107,754$.

Forrest, A. D., Fraser, R. H., and Priest, R. G., Brit. 3. Psychiat. 1965, 111, 243 .

1. Bruhn, J. G., F. ment. Sci., 1962, 108, 772.

is Greer, S., Brit. F. Psychiat., 1964, 110, 698

is Dreer, S., Brit. Ripley, H. S., and Jackson, J. K., Arch. gen. Psychiat. 1965, 12, 213 .

- Sharp, V. H., Glasner, S., Ledermann, I. I., and Wolfe, S., Psychiatry, $1964,27,127$.

I* Borowitz, G., 1963, quoted by Brown, F., Brit. Y. Psychiat., 1966, 112, 1035.

in Kay, D. W. K., Beamish, P., and Roth, M., Ibid., 1964, 110, 668.

a Pitts, F. N., Meyer, J., Brooks, M., and Winokur, G., Amer. Y. Psychiat., 1965, 121, Suppl. pp. 1-10.

so Munro, A., Brit. F. Psychiat., 1966, 112, 443.

:2 Munro, A., Brit. f. Psychiat. . P. F., ibid., 1966, 112, 459.

"2 Gregory, I., Amer. F. Psychiat.. 1958, 115, 432. 1352.

*t 135 ibid., 1966, 2, 1355.

so Gregory, I., Arch. gen. Psychiat., 1965, 13, 99.

- Brown, F., and Epps, P., Brit. Ұ.'Psychiat., 1966, 112, 1043.

Brown, ibid., 1966, 112, 1035 . distortion of father-child relationships may be more important. Prospective studies are urgently needed. ${ }^{25}$

F. Brown and P. Epps ${ }^{26}$ have compared the incidence of parental loss among children with neuroses and children with disorders of conduct only; the children were attending London child guidance clinics. Disorders of conduct were associated with divorce or separation of parents, illegitimacy, adoption, and having step-parents, but not with death of a parent. When the child was at home with both parents, neurosis was the commoner form of disorder. F. Brown ${ }^{27}$ also found parental loss or absence to be more frequent among male and female prisoners than in the general population. Here again the multiplicity of factors is apparent, as is the difficulty of obtaining suitable control samples from comparable strata of society.

The immediate effects of parental bereavement on children have received relatively little study. Some families withdraw closely into themselves, others break up. Experience with adult patients shows that death of a parent or member of the family in childhood is often remembered as highly traumatic, and, while the current approach to this problem seems to be to encourage forgetting, there may be a case for a more direct and frank approach, at least with older children.

The long-term social consequences of bereavement may entail " the total disintegration of the child's environment as he had come to expect and understand it."9 If the mother must take on the role of breadwinner, the child may effectively lose both parents. Increased monetary grants for widowed parents, enabling mothers to remain at home to look after young children and fathers to secure adequate mother substitutes and to keep the family together, would seem to be desirable on social grounds. The ill effects of bereavement are attributable in some measure to the adverse social circumstances that flow from it, and these are potentially avoidable. Society has therefore the power to reduce the number of emotionally disturbed and maladjusted individuals in its midst.

\section{Idiopathic Haemochromatosis}

Some debate has recently been concerned with the aetiology and pathogenesis of haemochromatosis. So much so, in fact, that it was included along with anticoagulants in a recent book entitled Controversy in Internal Medicine. ${ }^{1}$ In practice there are two types of patient that the physician is likely to encounter.

Firstly, a patient may present showing all or some of the classical clinical signs of idiopathic haemochromatosisnamely, bronzed pigmentation, diabetes, cirrhosis, and gonadal atrophy - the cirrhosis being shown by liver biopsy to be associated with massive deposition of iron in the liver. There may be a suggestive family history of the disease. Though the incidence of familial cases is only $1 \%$ of the total reported, ${ }^{1}$ systematic surveys have shown a much higher incidence in the immediate relatives of minor clinical signs, raised level of serum iron, or hepatic siderosis. $R$. Williams and his colleagues ${ }^{2}$ from London found excess free iron in hepatic biopsy sections from 28 of 46 relatives examined, though clinical signs of the disease were slight and only one relative had cirrhosis. L. W. Powell in Australia estimated that body stores of iron were increased in 16 out of 63 
relatives. $^{3}$ Most recently S. P. Balcerzak and colleagues from the U.S.A. have reported increased body stores of iron in 13 out of 28 relatives from three families studied in detail. ${ }^{4}$ The pattern of inheritance is variously described as dominant with incomplete expression or recessive with the heterozygote showing some abnormality. The clinical association of the fully developed disease with alcoholism ${ }^{1}$ suggests, however, that environmental factors in addition to a genetic defect are necessary for full expression of the disease.

Recently P. S. Davis and his colleagues ${ }^{5}$ have reported decreased amounts of gastric iron-binding protein; a substance which it is believed normally inhibits absorption of iron. On the other hand, A. Mazur and M. Sackler ${ }^{6}$ have found abnormally low levels of xanthine-oxidase activity in the liver, and suggest that this leads to a slow release of hepatic iron. This together with a moderate increase in absorption could account for progressive accumulation of iron in the tissues. The absorption of iron, however, is usually within the normal range. The basic defect is not clearly known. Absorption of iron is within the normal range when the patient is first seen, ${ }^{47}$ though it increases rapidly during venesection therapy and remains high in the majority of cases followed up after completion of treatment. ${ }^{7}$ Increases in absorption of iron have also been found in the relatives. In one series $55 \%$ of 29 close relatives showed increased values. ${ }^{8}$ In the families described by S. P. Balcerzak and colleagues relatives with increased iron stores of any size had normal values for absorption, whereas absorption was increased in 5 out of 11 asymptomatic relatives with normal iron stores. ${ }^{4}$ These findings suggest a primary increase in absorption which is suppressed as stores enlarge. However, only a small increase in absorption, if maintained, is necessary to account for a disease presenting in middle life. What is needed is knowledge of the balance between absorption and loss in the individual patient over a period of time rather than a comparison of his absorption value with the inevitably wide range found in control subjects.

The second type of patient the physician may be asked to see is one who shows the clinical signs of haemochromatosis but in whom liver biopsy shows only a slight to moderate excess of iron. The siderosis appears out of keeping with the extent of liver damage, and there may also be evidence from previoss biopsies that cirrhosis preceded the deposition of iron. ${ }^{9}$ A number of factors may be responsible for the siderosis. Patients with an alcoholic cirrhosis may have had an increased intake of iron ; wine particularly has a high iron content. $^{10}$ Iron absorption is often increased in cirrhosis, ${ }^{11}$

\footnotetext{
1 Controversy in Internal Medicine, edited by F. J. Ingelfinger, A. S. Relman, and M. Finland, 1966, Philadelphia.

Williams R., Scheuer, P. J., and Sherlock, S., Quart. F. Med., 1962, 31, 249.

- Powell, L. W., ibid., 1965, 34, 427.

- Balcerzak, S. P., Westerman, M. P., Lee, R. E., and Doyle, A. P., Amer. F. Med., 1966, 40, 857.

- Davis, P. S., Luke, C. G., and Deller, D. J., Lancet, 1966, 2, 1431

: Davis, P. S., Luke, C. G., and Deller, D. J., Lan 25 .

Williams, R., Manenti, F., Williams, H. S., and Pitcher, C. S., Brit. med. F., 1966, 2, 78 .

Pitcher, C. S., Parsonson, A., and Williams, H. S., Lancet, 1965 , 1,1243 .

- Sabesin, S. M., and Thomas, L. B., Gastroenterology, 1964, 46, 477.

- MacDonald, R. A., Hemochromatosis and Hemosiderosis, 1964, Illinois.

$"$ Greenberg, M. S., Strohmeyer, G., Hine, G. J., Keene, W. R., Curtis, G., and Chalmers, T. C., Gastroenterology, 1964, 46, 651.

"Callender, S. T., and Malpas, J. S., Brit. med. F., 1963, 2, 1516.

"I Grace, N. D., and Balint, J. A., Amer. F. dig. Dis., 1966, 11, 351. enterology, 1965, 49, 667.

is Walsh, R. J., Perkins, K. W., Blackburn, C. R. B., Sandford, R., and Cantrill S., Aust. Ann., Med., 1963, 12, 192., 16 Fielding, J., O'Shaughnessy, M. C., and Brunström, G. M., f. clin.

17 Smith, P. M., Studley, F., and Williams, R., Lancet, 1967, 1, 133.
}

this being due to associated pancreatic damage, ${ }^{12}$ to haemolysis, to interference with utilization of folic acid and vitamin $\mathbf{B}_{12}$, or simply to liver damage. Collateral shunting of portal blood may also be important. Some patients have developed clinical haemochromatosis after a portacaval shunt, though the amount of excess iron in such cases may be less than 3 g. $^{13}$

Because of the frequent finding of siderosis in primarily alcoholic cirrhosis and the repeated failure to produce haemochromatosis experimentally in animals by iron overloading alone, R. A. MacDonald ${ }^{10}$ has proposed that idiopathic haemochromatosis is merely one end of a range of states comprising cirrhosis and siderosis. Most workers find, however, that the overlap between the two groups described is not as great as MacDonald suggests. Furthermore, L. W. Powell ${ }^{3}$ could find increased iron stores in only 1 out of 34 relatives of patients with an alcoholic cirrhosis and secondary siderosis as compared with the 16 out of 63 relatives of patients with idiopathic haemochromatosis mentioned above.

The response to venesection therapy in idiopathic haemochromatosis is usually gratifying. Pigmentation and hepatomegaly decrease, and in some cases there is improvement in glucose tolerance. One patient has been described in whom serial biopsies showed reversal of the cirrhosis. ${ }^{14}$ Venesection therapy in cirrhosis with a slight secondary siderosis would hardly seem worth while, but its value both in these and in the occasional severe case requires further assessment. The question also arises how far should relatives of patients with idiopathic haemochromatosis be investigated and treated. Unfortunately the serum level of iron and the percentage saturation of the total iron-binding capacity are poor screening tests, since the normal ranges are wide and the serum level of iron may show spontaneous fluctuations. An estimate of the body's store of iron can be obtained by measuring urinary excretion of iron over 6 or 24 hours after injection of the iron chelators calcium D.T.P.A. or desferrioxamine. ${ }^{3}$ is Alternatively the total chelatable iron stores can be estimated by the differential ferrioxamine test of J. Fielding. ${ }^{16}$ Though these tests of iron excretion may not show minor increases in iron storage, they will detect the more severely affected relatives. In these the next stage is liver biopsy. The risk of this in experienced hands is low, and, though some physicians have recommended that all affected relatives should be treated by multiple venesections, such therapy is probably best reserved for those with histological evidence of tissue damage as well as siderosis.

\section{Anaesthesia for Dental Extractions}

The deaths and less disastrous consequences of anaesthesia given for dental extractions have for some years now been a subject of study and debate. They are at present being inquired into by a Ministry of Health committee, and its report is awaited with interest. A growing realization of the dangers of dental anaesthesia, together with better training in its techniques, has probably helped to lower the number of deaths from the high level of 22 in 1952 in England and Wales to the present 4 to 6 per year.

For many years after F. W. Hewitt ${ }^{1}$ popularized the addition of oxygen, little progress was achieved except for the 